Salze und auf schwefelsaures Kupferoxyd insbesondere. ? ouf, und werden durch Abkühlen oder Verdampfen wieder anverïndert erhalten, indem die Salzsäure keine Veränderung irgend einer Art bervorzubringen scheint.

Wenn man neutrales schwefelsaures Eisenoxydul in Salzsäure löet, so liefert die Flüssigheit bein Krystallisiren unrerändertes schwefelsaures Salz und Eisenchlorid, zuweilen entbält des so erhaltene schwefelsaure Eisen seine gewöhnlicbe Menge Krystallwasser; in andern Fällen jeduch habe ich ein Salz erhalten, welches der Analyse nach gab:

Schwefelsäure $\quad 18,7 \quad \mathrm{SO}_{3}=19,5$

Eisenoxydul $\quad 16,7 \mathrm{Fe}_{2} \mathrm{O}=17,3$

Wasser u. Verlust $\frac{14,63 \mathrm{H}_{2} \mathrm{O}}{50,0}=\frac{13,2}{50,0}$

Die Krystalle waren jedesmal so znsammengehäuf, dafs ibre Form nicht genau bestimmt werden honnte; sie waren durchscheinend, härter, und von eineın viel helleren Grün, als gewöbnlich Kupfersalze sind; sie sind vollkommen beständig, und geben in Wasser gelöst Krystalle ron schwefelsaurem Eisen mit der gewöhnlichen Menge Wassers.

Schwefelsaure Thonerde krystallisirt aus ibrer Lösung in Salzsäure unverändert, and $z$ war in viel schönern Tufeln als aus Wasser. Auflösungen ron schwefelsaurem Nickel oder Quecusilber in Salzsäure geben diese Salze un rerändert wieder.

\title{
Ueber die Zusammensetzung des Thebains (Paramorphins);
}

von Demselbers.

Der Güte des Herra Profeseor Liebig rerdanke ich die Benutzung einer sich darbietenden Gelezenheit, um die Zusammensetzung und Eigenschaften diesi, seltenen organischen Base zu untersucben, welcbi beiranatlich durch Pel. 
8 Ueber die Zusammenseltung des Thebains (Paramorphitis).

letiè and Thiboumerry lürzlich der langen Reihe der Bestandtheile des Opiums hinzagefügt wurde. In Betreff der Reiuheit der hiezu verwendeten Probe genügt es zu bemerken, dafs dieselbe ron Herrn Apotheker $\mathrm{Me} \mathrm{C} k \mathrm{k}$ in Darmstadt dargestellt, und Herrn Professor Liebig übergeben worden war.

Der Unterschied zwischen den analytischen Resultaten von Pelletier und Couerbe ist, besonders in Bezug auf die Menge des Stickstoffs, so bedeutend, dafs diefs allein schon ouf die Nothwendigkeit einer weitern Untersuchung hinweist. Man wird dieses auf den ersten Blick hinreichend. bestätigt finden, denn nach den Angaben des Journal de Pharmacie, Novembre 1835, Annal. d. Pharm. B. XVI. S 48., erhielt Pelletièr:

\begin{tabular}{lr} 
Kohlenstoff & 7,310 \\
Wasserstoff & 6,290 \\
Stichstoff & 4,408 \\
Samerstoff & 17,992 \\
\cline { 2 - 2 } & 100,000,
\end{tabular}

woraus er dieselbe Formel, wie fitr das Morphium $\left(\mathrm{C}_{34} \mathrm{H}_{39}\right.$ $\mathrm{N}_{2} \mathrm{O}_{6}$ ) ableitete, und indem er diese neu entdechte Basis mit jener isomerisch betrachtete, bezeichnete or sie mit dem Na. men Paramorphin.

Couerbe erbielt seinerseits (Annales de Chimic, Tom. 59 Pag. 156., Annal. der Pharm. B. XVII. S. 173.)

\begin{tabular}{lc} 
Kohlenstoff & 71,976 \\
Wasserstoff & 6,460 \\
Stickstoff & 6,385 \\
Sauerstoff & 15,179 \\
\hline & 100,000,
\end{tabular}

und die Formel $\left(\mathrm{C}_{25} \mathrm{H}_{27} \mathrm{~N}_{2} \mathrm{O}_{4}\right)$, welche mit der des Morphiums durchaus nicht zusammenhängt, wefshalb er die Benennung Paramorphin durch Thebain ersetzte, womit heino theoretische Beziehung verknüpt ist. 
Ueber die Zusammensetzung des Thebains (Paramorphins).

Ohne mich bei dem Aufzählen des Verhaltens dieses Stoffes gegen Agentien zu rerweilen, gebe ich sogleich die analytischen Resultate.

Nro. 1. 0,434 Substanz gaben: 0,265 Wasser.

$$
\text { 1,168 Kohlensäure, }
$$

woraus man für 200 Theile erhält:

$$
\begin{array}{lr}
\text { Hohienstoff } & 74,41 \\
\text { Wasserstoff } & 6,78 .
\end{array}
$$

Nro. II. 0,53o Substanz gaben: 0,329 Wasser.

1,420 Kohlensäure,

welches für 100 entspricht:

$$
\begin{array}{lr}
\text { Kohlenstoff } & \mathbf{7 4 , 0 7} \\
\text { Wasserstoff } & 6,89 .
\end{array}
$$

Nro. III. 0,4315 Substanz gaben bei der T'emperatur von $16,5^{\circ} \mathrm{C}$. und einem Barometerstand von $0,745 \mathrm{M}$. an feuch. tem Stichgas 24,5 Cub. Cent., welches 22,19 Cubilicentimeter trocknen Gases bei Null Graden und $0,76 \mathrm{M}$. Bar. entspricht, welches in 100 gleich ist:

\section{Stickstoff $\mathbf{6 , 9 4}$.}

Dicse Resultate werden durch folgende theoretische Forsnel rollständig ausgedrïclit:

\section{Gefunden.}

I.

II.

$$
\begin{array}{rl}
25 \mathrm{C} & =1910,925-74,57-74,41-74,07 \\
2 \mathrm{~N} & =177,036-6,89-6,94-6,94 \\
28 \mathrm{H} & =174,714-6,83-6,7^{8}-6,89 \\
3 \mathrm{O} & \equiv 300,000-11,71-11,87-12,10 \\
\hline 2562,67^{5} 100,00100,00 & 100,00 .
\end{array}
$$

An der Bestätigung der erhaltenen Formel durch die Analyse eines Salzes dieser organischen Base fand ich mich durch unüberwindliche Schwierigkeiten gebindert, indem, wie schon Pelletièr richtig bemertite, ihre Verbindungen mit Säuren eben so wenig bestimmt, als unkrystallisirbar scbeinen. 
10 Veber die Zusammensetzung des ihehuins (Paramorphins).

Um eine Annäherung des Atomgewichtes zu erhalten, liels ich trocknes Chlorwasserstoffgas über eine gewisse Menge ron Thebain streichen, bis die Aufnahme desselben dem Anscheine pach beendigt war, wobei jedoch die beobachteten Erscheinungen sehr unbefriedigender Art waren. Der Erfolg ist hier ausgefuihrt:

Nro. I. 0,392 Substanz wurden der Einwirkung ron trocknem Chlorwasserstoffgas ausgesetzt, während die, das Thebain enthaltende Höhte in kochendes Wasser tauchte. Die Masse wurde gelbbraun, harzartig, und sie war theilweise geschmolzen, als die Absorbtion beendigt zu seyn scbien.

Es war hier aufgenommen worden 0,065 Salzsäure, oder 100 Thebain batten 16,58 Salzsäure aufgenommen.

Nachdem man aun das Wasserbad entfernte, wurde der Gasstrom bei gewöhnlicher Temperatur unterbalten, worauf einige Erwörmung statt fand, und noch 0,068 oder 17,35 Procenc Salzsäure anfgenommen wurden.

Es hatten demnach 100 'Thebain aufgenommen:

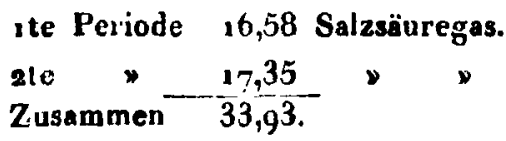

Nro. II. $0,47^{8}$ Thebain wurden ohne Anwendung ron Wärme der Einwirkung eines trockenen Gasstromes von Salzsïure unterworfen. Es entwickelte sich bedeutende Wärme, die Masse schmolz, wurde braun und harzäbnlich, und nach vollendeter Reaction fand sich, da 53 0,156 oder 32,64 Pro. cent absorbirt worden waren. Beim Erbitzen gab diese Masse etwas Salzsäure ab, aber es schien, als ob ein Theil der Base cinc Zersetzung erlitten bätte, so beld als ein Drittel der Säure entwickelt worden war.

Die Ergebnisse machen es üufserst wabrscheinlicb, dafs 
diese Base mit Salzsäure in wenigstens zwei Verbältnissen vich rerbinde, ron welchen die saure Verbindang die dop. pelte Sïuremeage der andern entbält. Beide sind jedoch beineswegs so bestimmt, um eine Ableitung des Atomgewichtes za gestatten.

Man hat nach deaselbea :

100 Basis absarbiren 33,93, gebend als Atomgewicht $1341: 2682$.

\begin{tabular}{|c|c|c|c|c|c|c|c|c|c|}
\hline on & $\nu$ & 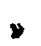 & $\nu$ & 32,64 & $y$ & $\geqslant$ & 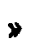 & 》 & $1394: \mathbf{2 7 8 8}$ \\
\hline $\mathbf{0}$ & 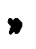 & $\bullet$ & $\nu$ & 16,58 & • & $y$ & 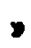 & $\%$ & 2745. \\
\hline 00 & ఐ & 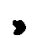 & $*$ & 27,35 & $\Rightarrow$ & 》 & $\nu$ & 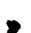 & 262 \\
\hline
\end{tabular}

Jedenfalls ist das Atomgewicht zu hoch, da durch den. gescbmolzenen Theil der Verbindung das Thebain gleichsam eingehüllt und verhindert wird, die gehörige Menge des suren Gases aufzunehmen.

Couerbe schelat eine Verbindong erhalten zu baben, welche noch weniger Säure enthält, und zwar genau den viertea Theil der gesättigten Verbindung, indem er fand, dafs 100 Thebain 8,35 Salzsäure aufnehmen, woron er demungeachtet ein Atomgewicht gleich 2678 ableitet. Es war mir nicht möglich, einen Körper von dieser Zusammensetzung dorzustellen.

In Couerbe's Abhandlung über diesen Gegenstand rerdient noch ein Umstand in Erwägung gezogen zu werden, der nitulich, dafe nicht erwïhnt ist, ob er eine wasserhaltige Substanz analysirte, oder nicht, obgleich er versichert, dafs das Thebais 4 Procent Wasser enthalte; do der Unterschied des Hohlenstoffgehaites unserer Analysen dem ersten Bliok mach daher zu rübren scheint, dafs er das Hrystallwasser nicht entferat haben möcbte, 10 ist die Bemerkung nơthig, dafs ich die Krystalle vollkommen wasserfrei fand. - Das von mir behandelse Thebain kann obne Gewichtsrerlust geschmolzen werdea, and nimmt als Pulver nur sehr wenig hygrometrische Fuchtigheit anf, 